\title{
Siltation of Ore Particles in Leaching Tanks: Causative Factors and Mitigation Measures*
}

\author{
${ }^{1}$ R. Osei, ${ }^{2}$ G. B. Abaka-Wood, ${ }^{1}$ G. Ofori-Sarpong and ${ }^{1}$ R. K. Amankwah \\ ${ }^{1}$ University of Mines and Technology, P.O. Box 237, Tarkwa, Ghana \\ ${ }^{2}$ University of South Australia, Adelaide, Australia
}

Osei, R., Abaka-Wood, G. B., Ofori-Sarpong, G. and AmankwahR. K. (2016) "Siltation of Ore Particles in Leaching Tanks: Causative Factors and Mitigation Measures", Ghana Mining Journal, Vol. 16, No. 2, pp. 51 57.

\begin{abstract}
Siltation involves the accumulation of sediment over a considerable period of time and this may occur in closed systems like leaching tanks. Most mining companies in Ghana experience siltation problems during leaching of gold ore. This paper examines the potential causes and possible mitigation measures of siltation. Particle size analysis, slurry settling rate tests and agitation efficiency analysis were used in identifying causative factors of siltation whiles deflocculation test and grind analysis were conducted to ascertain mitigation measures. Results from the study indicated that, high settling velocity of particles, inefficient milling and classification, poor slurry agitation and particle flocculation were the major causative factors leading to siltation. Size analysis results revealed $\mathrm{P}_{67}$ of $106 \mu \mathrm{m}$ instead of $\mathrm{P}_{80}$ of $106 \mu \mathrm{m}$, a situation which affects particle suspension by agitators leading to siltation. This study therefore suggests that increase in milling residence time and particle deflocculation are potential remediation measures for curbing siltation. Extended grinding of ball mill feed resulted in $94 \%$ passing $106 \mu \mathrm{m}$ while settling velocity was reduced by $71 \%$ after deflocculant addition at 1000 ppm.
\end{abstract}

Keywords: Siltation, Deflloculation, Settling Velocity, Grinding

\section{Introduction}

Most mineral extraction operations begin with a comminution process to liberate the mineral of interest. Comminution is the progressive reduction in the size of an ore to a suitable size range to liberate the mineral of interest from the worthless gangue material or shorten the travel distance of reagents during leaching. In a typical gold extraction plant where agitation leaching is employed, comminution may be accomplished stepwise through a circuit made of a primary crusher, Semi Autogenous Grinding (SAG) mill and ball mills. The SAG and ball mills generally have independent cyclones to classify their products (Wills, 2006; Amankwah and OforiSarpong, 2011).

In this era of low grade ores and low metal price regimes, most plants now operate on high tonnage and leaching is conducted at pulp densities in excess of $50 \%$ solids instead of conventional values between $40 \%$ and $45 \%$. Thus, the classifier overflow material is prepared for leaching by passing it through a thickener to obtain the appropriate feed density in excess of $50 \%$ solids. The thickening process requires the use of flocculants and this chemical that assists in thickening may have a carry-over effect and also cause repeated settling or siltation during leaching in tanks.

The presence of coarse materials in leaching circuits also affects particle suspension by agitators due to the smaller surface area and higher drag forces of such particles in a turbulent flow regime. These effects cause them to gravitate to the bottom of containing vessels as a result of gravitational, centrifugal or any external force acting on the particle and thus, enhance sedimentation (Walsh, 1988; Concha, 2009). The accumulation of such sediments over a considerable period of time leads to siltation, a situation which is faced by most mining and mineral processing companies.

Siltation leads to the formation of a stationary bed at the bottom of the leach tank over a considerable period of time and is a major problem in agitation tanks, where particles intended for suspension get settled based on several factors. This process reduces the effective volume of leaching tanks available for leaching which also reduces the tonnage of ore that can be processed within a given residence time. Coarse gold particles present in such tanks gravitate to the bottom due to their high drag force and get locked up in the silt material. Coarse gold locked up in silt materials in some gold processing plants are as high as $53 \mathrm{~g} / \mathrm{t}$ (Konadu et al., 2014). In this research, causative 
factors for siltation of tanks in the Carbon-in-Leach Plant of Gold Fields Ghana Ltd at Tarkwa were investigated. The mitigation measures to siltation are also proposed.

\section{Resources and Methods Used}

\subsection{Materials}

The samples used in this study were Semi Autogeneous Grinding (SAG) mill cyclone overflow product, ball mill feed, ball mill cyclone overflow product, pre-leach thickener feed, leach feed and silt material obtained from the mineral processing plant of Gold Fields Ghana Limited (GFGL).The silt samples were obtained from a $17.1 \times 15.8 \mathrm{~m}$ (height $\mathrm{x}$ diameter) drained leaching tank.

\subsection{Methods}

Screen analysis, settling rate test and agitator efficiency analysis were carried out on the metallurgical plant whiles grind analysis and deflocculation test were carried out in the Minerals Engineering laboratory of University of Mines and Technology.

\subsubsection{Screen Analysis}

Wet screening was conducted on four randomly sampled silt material to access the particle size distribution of the silt materials. The nest of screens used were built according to the Tyler series with $6700 \mu \mathrm{m}$ as the coarsest screen aperture size and $106 \mu \mathrm{m}$, the lowest. Ball mill cyclone overflow sample, composited for a period of two weeks, was wet-screened using a $106 \mu \mathrm{m}$ screen to determine the percentage passing $106 \mu \mathrm{m}$.

\subsubsection{Settling Rate Test}

Settling rate tests were conducted on the SAG and ball mill cyclone overflow samples and the thickener feed in a graduated 1000-ml measuring cylinder for a period of 40 minutes by monitoring the change in slurry boundary at 30 seconds intervals. The results were plotted graphically and equation of the curve generated to extend the time on the settling curve using exponential decay curves. The experiment was run in triplicate. Settling velocities of the samples together with a standard sample milled to $80 \%$ passing $106 \mu \mathrm{m}$ were determined.

\subsubsection{Agitation Efficiency Analysis}

Measurements were taken on a fresh agitator blade and a worn out blade using an engineering tape. Design measurement of the leaching tank (diameter, height, freeboard and agitator off-bottom distance) was obtained and inference drawn from them. Visual observation was conducted in a drained tank containing silt material.

\subsubsection{Grind Analysis}

Ball mill feed samples from the plant which comprises of the SAG mill cyclone underflow and the ball mill cyclone underflow were milled at $65 \%$ pulp with reference to the milling pulp density of the processing plant, for 5, 10, 15 and 20 minutes. Initial percent passing $106 \mu \mathrm{m}$ of the ball mill feed sample was estimated via wet screening. Final milled products obtained were wet screened and the percentage passing $106 \mu \mathrm{m}$ screen aperture size, estimated.

\subsubsection{Deflocculation Test}

One kilogram dry mass of leach feed sample having particle size distribution of $(+220 \mu \mathrm{m}-75$ $\mu \mathrm{m})$ was pulped to $56 \%$ to obtain material with pulp density similar to that of the metallurgical plant. Settling rate tests were conducted on the sample for 60 minutes without deflocculant addition and the fall in slurry boundary noted every 2 minutes. This was to serve as a control for the subsequent experiment, which was replicated using caustic as a deflocculant at different concentrations for 60 minutes and the fall in slurry boundary monitored for every 2 minutes. The equation of the curve was generated and time extended to plot settling curves using exponential decay curves.

\section{Results and Discussion}

\subsection{Screen Analysis of Silt}

The particle size distribution of the silt materials was investigated and Fig. 1 shows the cumulative percentage passing for the various screen sizes. This reflects the various size ranges of particles in the silt material, and the coarse nature gives a clear indication of the poor grinding and classification processes. The $80 \%$ passing size of the silt material was estimated to be $1700 \mu \mathrm{m}$ which is far higher than the design size range $\left(\mathrm{P}_{80}\right.$ of $\left.106 \mu \mathrm{m}\right)$ for leaching. Indeed, $94 \%$ of the silt material had particle size range above the design size of $106 \mu \mathrm{m}$. Coarser particle sizes impact adversely on particle suspension by agitators due to the high drag forces of such particles which gives them high settling velocities, thus leading to siltation (Walsh, 1988). 


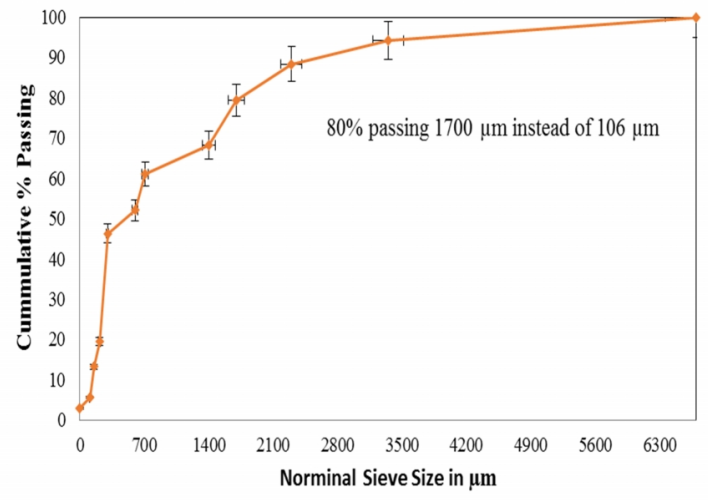

Fig. 1 Screen Analysis of Silt Material

\subsection{Screen Analysis of Ball Mill Cyclone Overflow}

Following a 14-day campaign, the percentage of material passing $106 \mu \mathrm{m}$ for the ball mill cyclone overflow, as shown in Fig. 2, indicates that $67 \%$ of the feed particles had sizes less than $106 \mu \mathrm{m}\left(\mathrm{P}_{67}\right.$ of $106 \mu \mathrm{m}$ ) instead of the design size of $80 \%$ passing $106 \mu \mathrm{m}\left(\mathrm{P}_{80} 106 \mu \mathrm{m}\right)$. According to Fig. 2, only two (2) out of the fourteen (14) samples were within the design leach feed size. This situation will put undue pressure on the agitators, hence creating suspension inefficiencies and enhancing feed particle siltation.

The coarse nature of the cyclone overflow may be ascribed to several factors including short residence time of feed materials in the ball mill as a result of the dwindling gold grade and/or gold prices which compels management to resort to processing high tonnage with constant residence time of feed in the mill to meet targeted tonnages. This in effect produces coarse mill products (Konadu et al., 2014).

Other contributing factors in the grinding circuit to the coarse cyclone overflow include inefficient classification by cyclones due to high tonnages and cyclone pressures which at some times exceed the design plant value of $(120-130) \mathrm{kPa}$. The state of mill liners may also affect grinding in cases of severe wear.

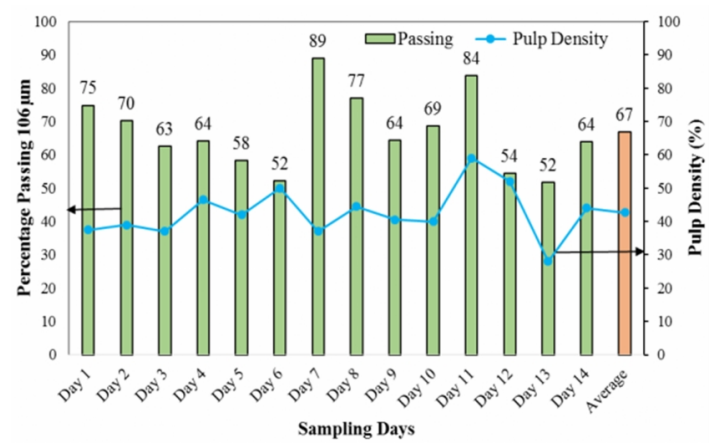

Fig. 2 Screen Analysis of Ball Mill Cyclone Overflow

\subsection{Settling Rate Test}

Fig. 3 (A to D) presents the effect of settling velocity on particle siltation in various systems. In all cases, settling velocity was high compared with a standard feed particle size with $\mathrm{P}_{80}$ of $106 \mu \mathrm{m}$. Settling velocity of the Ball Mill Cyclone Overflow (BMCO) was the highest followed by the Thickener Feed (TF) and the Sag Mill Cyclone Overflow (SMCO). The average of all the settling velocities of particles in these systems was high compared with the standard settling velocity of feed particle with $\mathrm{P}_{80}$ of $106 \mu \mathrm{m}$. High settling velocity of the BMCO is as a result of its coarse nature, having an average of $\mathrm{P}_{67}$ of $106 \mu \mathrm{m}$. The coarse nature gives it higher drag force which enhances settling (Walsh, 1988). The SMCO was expected to exhibit low settling velocity, but it turned out to be high irrespective of its fine particle size of $94 \%$ passing $106 \mu \mathrm{m}$ from a data received from the plant. This can be attributed to high $\mathrm{pH}$ values observed at the milling and classification unit, which introduces negative charge densities on the suspended particles nullifying the repulsive forces and causing them to sediment faster (Ersoy, 2004). The $\mathrm{pH}$ values observed at the milling and classification units were above 11.5 to as high as 13.75, which enhanced settling as the lime used in $\mathrm{pH}$ modification aids settling when in excess. The TF which is a blend of the BMCO and SMCO had a higher settling velocity as well. Feed from the TF undergoes flocculation which further increases its settling velocity as a result of the flocculants creating polymer bonds between feed particles and thus producing lumps with higher drag forces which causes fines to also settle. Such material, when forwarded to the leaching tanks, sediments faster leading to siltation due to some agitation inefficiencies.

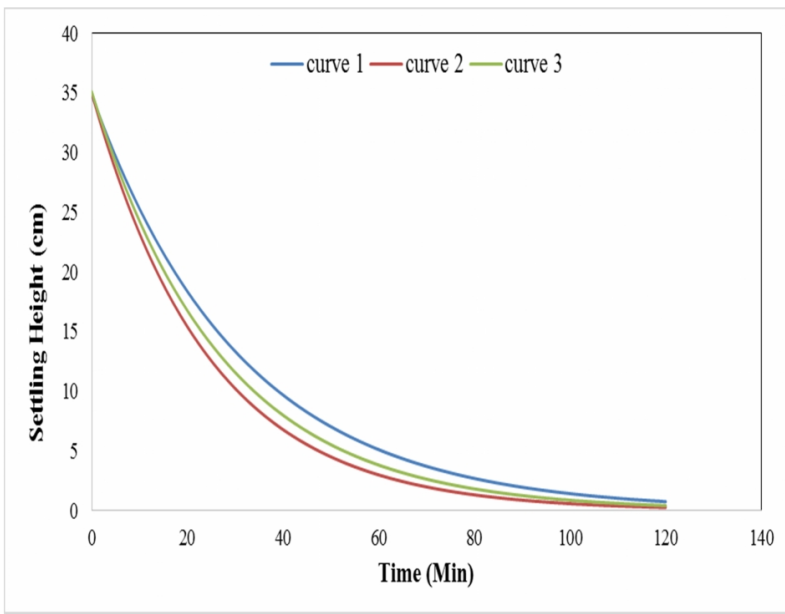

Fig. 3 (A) Ball Mill Cyclone Overflow Settling Curve (BMCO). Curves 1, 2 and 3 are Results of Replicates 


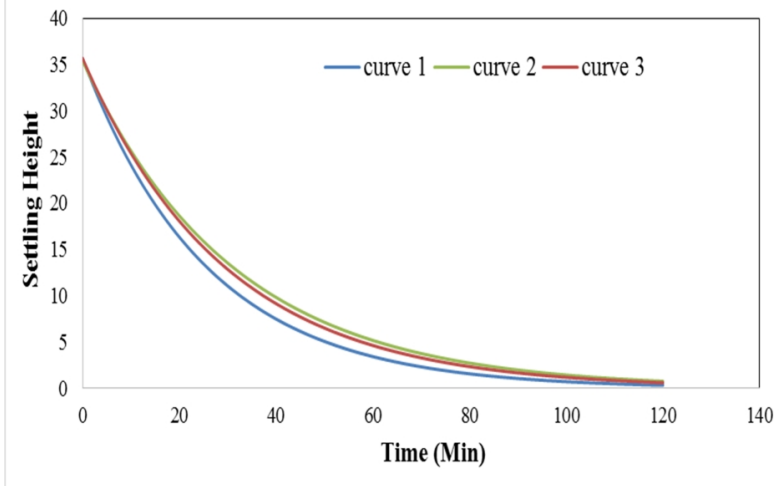

Fig. 3 (B) SAG Mill Cyclone Overflow Settling Curve (SMCO). Curves 1, 2 and 3 are Results of Replicates

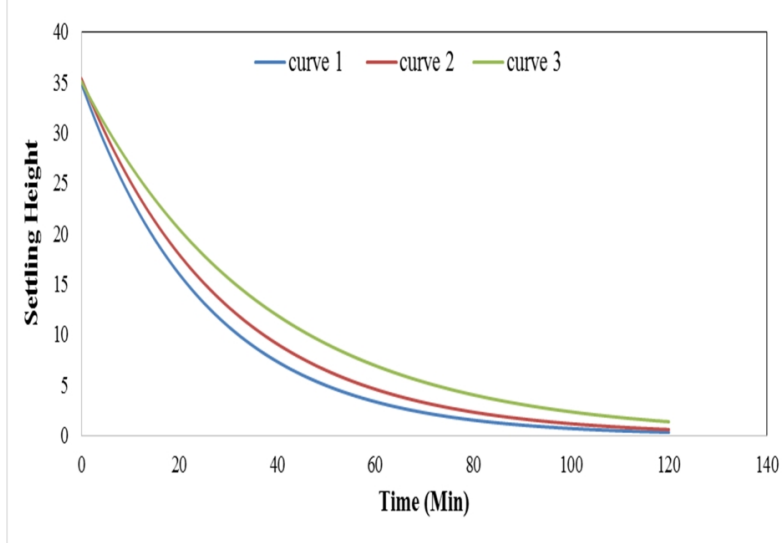

Fig. 3 (C) Thickener Feed Settling Curve. Curves 1, 2 and 3 are Results of Replicates

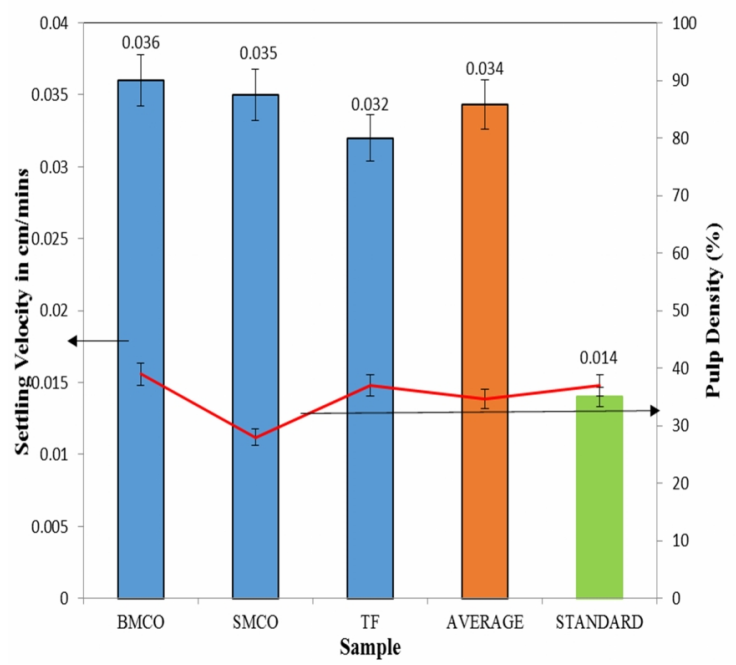

Fig. 3 (D) Average Settling Velocities of Particles in Various Systems

\subsection{Agitation Efficiency Analyses}

\subsubsection{Measurements}

Analysis of design measurements obtained from the plant indicated that, the off-bottom distance of the agitator was 19 feet $(5.8 \mathrm{~m})$ as indicated in Fig 4. Other measurements recorded are detailed in Table 4.2. Literature reveals that for maximum offbottom suspension of solids, an impeller location of $1 / 3$ the impeller diameter blade may be satisfactory (Anon, 2015). However, the off-bottom distance in the leaching tank exceeds that in literature. The diameter of the impeller blade was $5.2 \mathrm{~m}$ and from literature its off-bottom was supposed to be $1.7 \mathrm{~m}$ however, the off-bottom was $5.8 \mathrm{~m}$ which is three times higher and hence affects mixing efficiency. By reducing distribution of radial and axial forces introduced into the slurry by agitation, some areas are left unmixed. Feed particles with higher settling velocities located below the required off-bottom distance region are prone to settling leading to siltation.
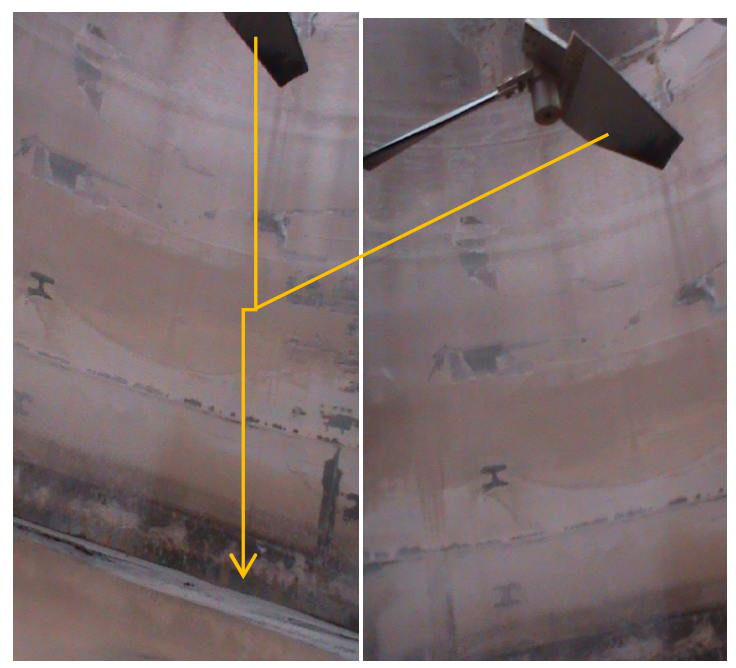

Fig 4 Agitator Off- Bottom

Table 4.2Measurements taken from the Plant

\begin{tabular}{|l|c|}
\hline PARAMETERS & MEASUREMENT (m) \\
\hline $\begin{array}{l}\text { off-bottom distance of } \\
\text { agitator }\end{array}$ & 5.8 \\
\hline diameter of leach tank & 15.8 \\
\hline height of leach tank & 17.1 \\
\hline $\begin{array}{l}\text { freeboard of leach } \\
\text { tank }\end{array}$ & 0.6 \\
\hline $\begin{array}{l}\text { length of fresh agitator } \\
\text { blade }\end{array}$ & 2.6 \\
\hline $\begin{array}{l}\text { length of worn out } \\
\text { agitator blade }\end{array}$ & 2.3 \\
\hline $\begin{array}{l}\text { perimeter of fresh } \\
\text { agitator blade }\end{array}$ & 6.6 \\
\hline $\begin{array}{l}\text { perimeter of worn out } \\
\text { agitator blade }\end{array}$ & 5.0 \\
\hline $\begin{array}{l}\text { \%ear of agitator } \\
\text { blade }\end{array}$ & 24.3 \\
\hline
\end{tabular}


Agitators tend to wear out with time due to friction between impeller blades and feed material as well as the presence of reagents and chemicals in the tank. Wearing of agitators affects mixing efficiency, by reducing total perimeter covered by the agitator. Such a situation favors siltation since the agitator's efficiency is reduced.

\subsubsection{Observation}

Visual observation in a drained tank showed that agitators encounter mechanical failure such as displacement (Fig. 5). Displacement of agitator blades highly affects mixing by reducing diffusion of radial and axial forces through the slurry causing feed particles to sediment leading to siltation. In Fig. 5, the displacement was on the lower impeller blade which led to a high silt build up in the tank; up to about $3 \mathrm{~m}$.

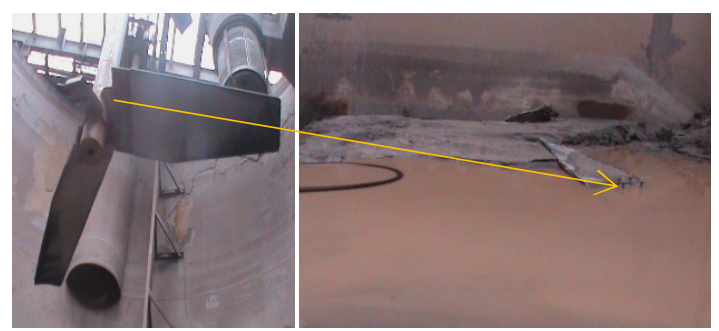

Fig. 5 Mechanical Failure of an Agitator Blade

\subsection{Grind Analysis}

Fig. 6 indicates the effect of grinding residence time on mill product. The initial percentage passing $106 \mu \mathrm{m}$ of the circulating load at time zero was $13 \%$ and from the results it was seen to be increasing with increasing grinding time. The trend is similar to that presented by Song et al (2012). With increasing residence time, the feed in the mill achieves maximum abrasion and impact from coarser feeds, steel balls and liners to cause particle size reduction which enhances particle breakdown. The required time for attaining 80\% passing 106 $\mu \mathrm{m}$ was estimated by interpolating between 10 minutes and 15 minutes and it was found to be 12 minutes, 22 seconds. Increasing grinding time would produce finer mill products with lower drag forces which would enhance particle suspension at an optimum $\mathrm{pH}$ by the agitator in the absence of mechanical failure.

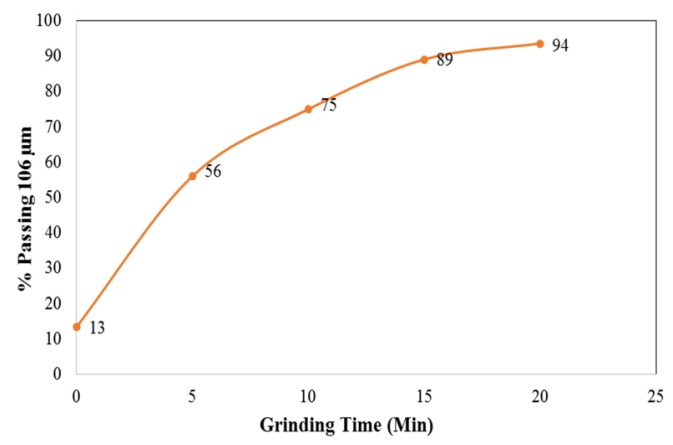

Fig. 6 Grind Analysis of Mill Feed

\subsection{Deflocculation Test}

Figure 7 (A and B) shows the drop in settling velocities of the leach feed upon addition of caustic as a deflocculant. This is as a result of the deflocculant creating a steric repulsion between the particles and also breaking polymer bonds between flocculants and feed particles. The deflocculant increases zeta potential of the particles, decreasing the attractive forces between the particles and in effect increasing repulsive forces. This is as a result of the presence of sodium ion in the deflocculant. It increases the electrical double layer between particles by being attracted by the negatively charged feed particle and in effect creating repulsion between neighbouring particles thus keeping them in a state of suspension (Larsson et al., 2012; Zchimmer and Schwarz, 2009). Settling velocity was seen to reduce by $71 \%$ at $1000 \mathrm{ppm}$ of caustic with reduction decreasing as concentration increased. At $10000 \mathrm{ppm}$, settling velocity reduced by $14 \%$ as a result of higher percent solids and deflocculant concentration leading to overlapping and superimposition of zeta potential of neighbouring particles (Zchimmer and Schwarz, 2009).

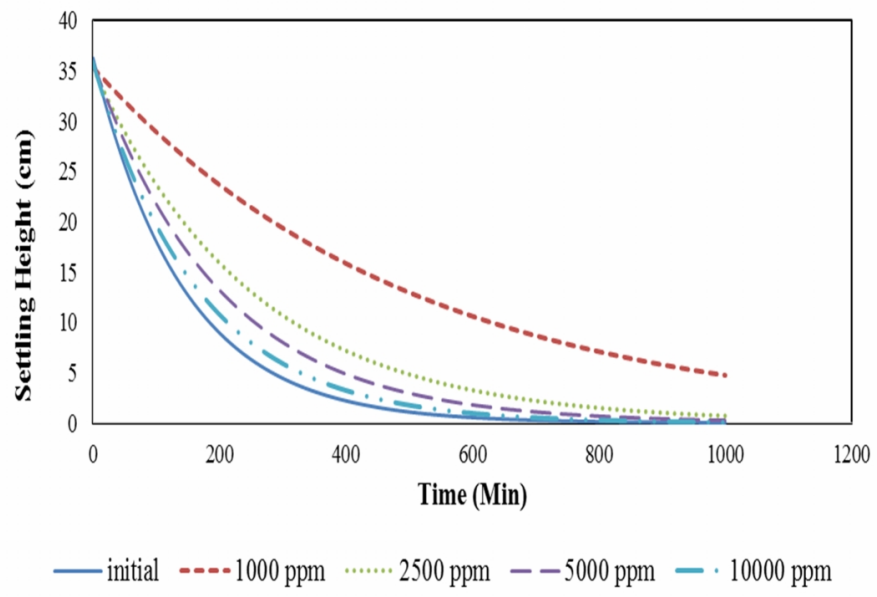

Fig 7 (A) Settling Curves obtained after Deflocculation Test

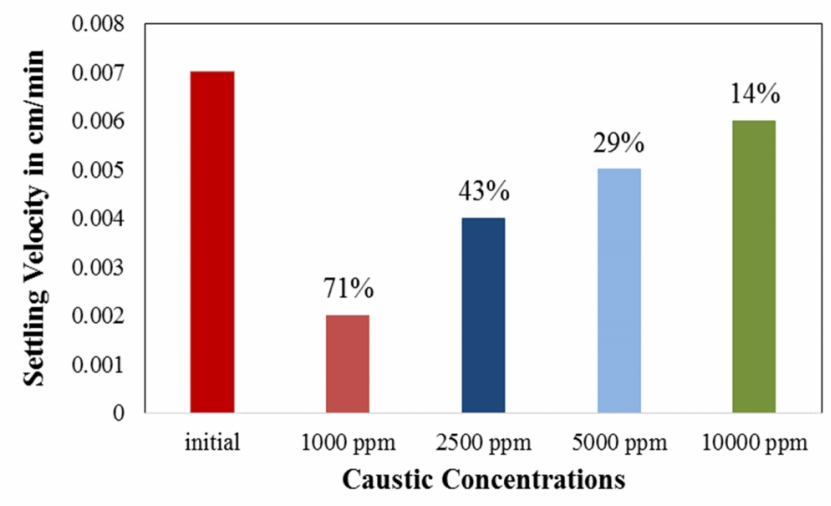

Fig 7 (B) Reduction in Settling Velocity with Deflocculant Addition 


\section{Conclusion}

Factors leading to particle siltation in gold leaching tanks and corresponding mitigation measures were investigated. It is comprehensible from the investigations that inefficient milling and classification, high settling velocities and agitation inefficiencies were the major factors leading to siltation. The result showed that the average percentage passing size for the ball mill cyclone overflow was $67 \%$ passing $106 \mu \mathrm{m}$ instead of $80 \%$ passing. The average settling velocity of the ore was also estimated to be $5.67 * 10^{-6} \mathrm{~m} / \mathrm{s}$. The efficiency of the agitator was also assessed with reference to its off-bottom distance which was 5.8 $\mathrm{m}$, three times higher than an expected distance of $1.7 \mathrm{~m}$. Mechanical failures and design measurements also contributed to the inefficiency of the agitator. However a drastic decrease in settling velocity was accomplished when caustic was used as a deflocculant at $1000 \mathrm{ppm}$. The results of this study therefore reveal that deflocculation and finer grinding are options for mitigating siltation in gold leaching tanks considering its causative factors. The authors thus propose the use of finer grinding and deflocculation as strategies to remediate siltation in gold mineral processing plants.

\section{Acknowledgement}

The authors gratefully acknowledge the assistance from the Gold Fields Ghana Ltd, Tarkwa Mine; Metallurgy Department and the University of Mines and Technology, Minerals Engineering Department.

\section{References}

Amankwah, R. K. and Ofori-Sarpong, G. (2011), "Microwave heating of gold ores for enhanced grindability and cyanide amenability", Journal of Minerals Engineering 24, pp. 541 - 544.

Anon.(2015), Mixing and Agitation,

http://www.pacontrol.com/process-informationbook/Mixing $\% 20$ and $\% 20$

Agitation\%2093851_10.pdf. Accessed: June 16, 2015.

Concha, F. (2009), "Settling Velocities of Particulate Systems", Department of Metallurgical Engineering, University of Concepción, 20 pp.

Ersoy, B. (2004) "Effect of $\mathrm{pH}$ and Polymer Charge Density on Settling Rate and Turbidity of Natural Stone Suspensions", International Journal of Mineral Processing, Elsevier Science \& Technology Books, pp. 207-216.

Konadu, K. T., Abaka-Wood, G. B. and OforiSarpong, G. (2014), "Gold Loses due to Silt Formation in Leaching Tanks", In: Proceeding of the 3rd UMaT Biennial International Mining and Mineral Conference, pp. 289-293.

Larsson, M., Hill, A. and Duffy. J., (2012), "Suspension Stability; Why Particle Size, Zeta

Potential and Rheology are Important", Annual Transactions of the Nordic Rheology Society, Vol. 20, 6 pp.

Song, J., Wang, F., Li, X., Zhao, L., Li, W., Huang, H. and Su. M. (2012), "Influence of Ball Milling Parameter on the Refined Effect of Quartz Sand", Second International Conference on Materials, Mechatronics and Automation Lecture Notes in Information Technology, Vol. $15,5 \mathrm{pp}$.

Walsh, D. E, (1988), "A Study of Factors Suspected of Influencing the Settling Velocity of Fine Gold Particles", Mineral Industry Research Laboratory 210 O'Neill Research Laboratory, University of Alaska Fairbanks, Fairbanks, Alaska 99775-1180, 43 pp.

Wills, B. A. (2006), Mineral Processing Technology, seventh edition, Elsevier Science \& Technology Books, Maryland Heights, Missouri, USA, $450 \mathrm{pp}$.

Zchimmer and Schwarz, (2009), Mechanisms of action of deflocculants and dispersants in ceramic bodies, Ceramics. GmbH \& Co. KG. Chemische Fabriken, Lahnstein, Germany, 15 pp.

\section{Authors}

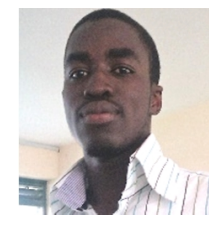

Richard Osei holds a BSc in Minerals Engineering from the University of Mines and Technology, Tarkwa, Ghana. He is a research assistant at Process Innovation Ghana (2015). His research interests includes extractive metallurgical processes, surface chemistry and microbial mineral recovery.

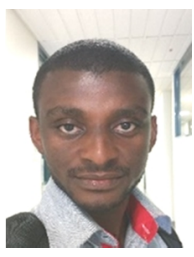

George Blankson Abaka-Wood, is a $\mathrm{PhD}$ candidate at the Future Industries Institute of the University of South Australia, Australia. $\mathrm{He}$ holds a BSc degree in Minerals Engineering from the University of Mines and Technology, Tarkwa. His research interests are in rare earth elements minerals beneficiation, comminution and CIL plant optimization issues. He is a member of Canadian Institute of Mining, Metallurgy and Petroleum.

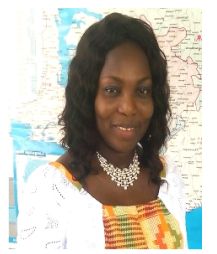

Grace Ofori-Sarpong is an Associate Professor of Minerals Engineering and employee at the University of Mines and Technology (UMaT), Tarkwa, Ghana. She holds a Bachelor of Science Degree in Metallurgical Engineering (Mineral Processing and Extractive Metallurgy) and a $\mathrm{MSc}$ in Environmental Resource Management, both from the Kwame Nkrumah University of Science and Technology, KNUST, Kumasi, Ghana. She also has a $\mathrm{PhD}$ in Energy and Mineral Engineering from the Pennsylvania State University, USA. Her areas of research interest include microbial-mineral interactions, recovery of precious metals, microwave processing, water quality monitoring and mine waste management. 
Richard K Amankwah is a Professor of Minerals Engineering at the University of Mines and Technology (UMaT), Tarkwa, Ghana. He was educated at Kwame Nkrumah University of Science and Technology, Ghana, Technical University of Clausthal,

Germany and Queen's University, Canada where he obtained a $\mathrm{PhD}$. His research interests include gold beneficiation, water quality management, microwave processing of minerals, smallscale mining, medical geology, microbial mineral recovery and environmental biotechnology. He is a member of the Ghana Institution of Engineers and Society for Mining, Metallurgical and Petroleum Engineers. 